\title{
Emotional Scaffolding as a Strategy to Support Children's Engagement in Instruction
}

\author{
Mi-Hwa Park \\ College of Education and Human Services, Murray State University, USA
}

Copyright $\bigcirc 2017$ by authors, all rights reserved. Authors agree that this article remains permanently open access under the terms of the Creative Commons Attribution License 4.0 International License

\begin{abstract}
Consideration of children's emotions in a classroom provides more opportunities for improvement in children's engagement. However, the literature about emotional scaffolding in early childhood settings is underdeveloped. This qualitative case study focuses on the construction and implementation of strategies of scaffolding emotions by two early childhood educators in a public elementary school. The data consist of participant observations, interviews, and documents. The analysis highlights three major themes: The participants' beliefs about self-identity, their understandings of students' emotions, and their feelings of school expectations and academic pressures. The findings show the way that beliefs, knowledge, and other contextual factors interact to produce emotional scaffolding strategies. This study discusses several points of difference that reveal the uniqueness for emotional scaffolding in early childhood contexts. This study finds that emotional scaffolding is a critical pedagogical tool that could help teachers reach developmentally appropriate practices for early childhood education in an age of accountability.
\end{abstract}

Keywords Emotional Scaffolding, Engagement, Early Childhood Education

\section{Introduction}

In recent years, early childhood educators in public education settings have experienced great pressure to meet the academic standards set by the nation, state, or district. This pressure reconstructs early childhood educators' teaching practices, encouraging them to focus more attention on children's academic achievements. This shift in emphasis, in turn, has led to the neglect of emotions. Early childhood educators have argued that they do not have time and energy to give to children's emotions in the classroom [10]. The dilemma of the early childhood educators in the time of cognitive-based standards may prevent them experiencing these new pressures from attending to children's emotions in instruction.

Influenced by cognitive science, the literature about emotion in early childhood has extended from investigations located within the boundaries of the emotional realm to investigations of the connection of the emotional with the cognitive domain. This literature criticizes an exclusive focus on academic success in assessment of school readiness in the early childhood context [1], [4]. For example, Blair [1] working in the field of human development, argued that emotional process assists children's self-regulated learning and effortful involvement in learning activities more than cognitive process does, and serves as a foundation for social and academic performance in early development. Hyson [4] also argued that preschool and kindergarten children's positive emotions, including interest, enjoyment, and happiness, experienced through classroom activities, have a central role in developing student attention, self-regulation, and long-lasting memory. Because emotion functions as a protective buffer, which fosters upward spirals toward future academic success, the literature argues that students' emotions should not be neglected in preparing them to become academically competent [4].

The neglect of emotions deprives children of the right to maximize their learning potential and deprives teachers of a valuable tool they could use to fulfill their responsibilities more effectively in an age of accountability. The current early childhood education situation calls our attention to the need of an empirically based theory for scaffolding emotion that goes beyond a reliance on the disposition of individual teachers. Such a theory would bolster teachers' understanding of the emotional aspects of teaching and learning and provide pedagogical knowledge about ways to incorporate emotions in instruction to increase children's engagement, which is a strong indicator of children's successful learning experiences [4]. Because of the need for a theory that would empower teachers to deal with emotions while succeeding in the present climate, the primary interest in this study was to look at early childhood educators' pedagogical decision-makings surrounding emotional scaffolding, and their motivations underlying these decisions. Two research questions guided this study. 
1. What are early childhood educators' strategies for emotional scaffolding?

2. How is emotional scaffolding constructed and implemented in the early childhood education context?

\section{Theoretical Framework}

Positive emotional experiences that enhance learning can be called emotional scaffolding, a term that borrows from Vygotsky's concept of scaffolding and combines it with an awareness of the role of emotion in the learning process [9]. The development of the theory of emotional scaffolding expands on Vygotsky's emphasis on affective dimensions of learning in the zone of proximal development. Since self-regulation and autonomy are central goals of academic scaffolding as Vygotsky [16] defined it, it seems as though attention to emotional scaffolding should be an integral part of the scaffolding process. The literature describing emotional scaffolding is still emerging, but provides important pathways for assessing the way that teachers engage students emotionally while teaching [7], [9], [12], [13]. The literature argues that emotional scaffolding is a powerful pedagogical tool that affects classroom interactions and students' emotional experiences.

I approached emotional scaffolding using Meyer and Turner's [9] definition, derived from their study of emotional interactions in middle-school classrooms: "Temporary but reliable teacher-initiated interactions that support students' positive emotional experiences to achieve a variety of classroom goals" (p. 244). They differentiated emotional scaffolding from other forms of teacher-student interactions, saying that teachers engaging in emotional scaffolding have clear classroom goals. Based upon previous literature about emotional scaffolding, they provided a list of these goals, which teachers use emotional scaffolding to reach: "Sustaining students' understanding of challenging concepts, students' demonstration of their competencies and autonomy, students' involvement and persistence, and students' emotional or personal experiences" (p. 245). Meyer and Turner emphasized the ultimate purpose guiding all of these aims: "increasing student achievement and autonomy" (p. 244). Because I consider emotional scaffolding to be a reciprocal concept, my study alters the framework slightly, encompassing all aspects of classroom emotion arising out of non-verbal communication and the teacher's responses to students.

\section{Method}

This study conducted two qualitative case studies in line with assumptions of the constructivist paradigm to capture the complexity of the dynamics of emotional communication between teachers and students. The participants were two early childhood educators (one preschool; between the ages of 3-4 years and one kindergarten; age 5) who are working in a public school located in a mid-sized city in Texas. They were purposefully selected because they both sensitively reacted to their students' emotions, their classrooms showed a high level of student engagement, and the level of positive verbal and nonverbal emotional interactions between the students and the teachers was higher in these classrooms

\section{Data collection}

Data were collected through interviews, field notes, observations, and documents. Each participant was observed for two hours a day, two days a week throughout the semester. I negotiated an observation schedule for each classroom, designed to capture each teacher's daily teaching practices without missing any part of the classroom schedule. I attempted to achieve equivalence in data collection by considering not only the amount of time I spent in each classroom, but also the type of instructional activity taking place in the classroom at the time.

I took up a position in an unobtrusive part of the classroom, and took notes on a laptop computer about the teacher's verbal and nonverbal expressions; her location in the classroom during different activities; the types of materials presented in class; the degree of freedom granted to the children to express their ideas and feelings; student responses to instructional materials and to the teacher in general; and the instructional contexts.

I also audio-and-videotaped classroom interactions using a camera set up on a tripod next to me to supplement my own typed notes and to increase the accuracy of my data by including subtle non-verbal interactions, which would be missed by audiotape recordings. In addition to recording happenings in the classroom, I kept reflexive analytic notes, which I wrote both during the class time and after my observations had ended for the day. These notes included feelings and ideas that surfaced during observations, as well as questions which I wished to ask the participants, and also served as preliminary analysis of the data. I also conducted weekly member checks with the participants, sharing all of my observational data and my interpretations.

Semistructured interviews were employed to understand the participant's invisible experiences, perceptions, interpretations, and feelings and to foster a climate in which the interviewee would feel free to express authentic feelings, in the hopes that this would result in a more honest set of responses [8]. Each participant was interviewed for approximately 60 minutes prior to the beginning of classroom observations, using a list of questions developed from my research questions. In conjunction with observations and collected documents, each participant was also engaged in various informal interviews. The frequency of these informal interviews relied on the ongoing process of observations and document collecting. Each informal interview took place during a convenient time for the participant and took 20-60 minutes. All interviews were audio-taped and transcribed. Throughout the interviews, I took reflexive analytic notes, which I integrated into my objectives for the next data collections. Additionally, all the 
transcribed interviews were given to each participant for a weekly member check, fulfilling the goal of establishing trustworthiness [8].

Documents were collected without disturbing the participants' practices. Collected documents included the participants' lesson plans, teaching materials, classroom schedule, class roster, parent and student notes, and district standard testing results. These documents were compared with observations and interviews on an ongoing basis in my reflexive analytic notes to deepen my understanding of the context-specific teaching practices of emotions.

\section{Data analysis}

Data analysis occurred simultaneously as the data were collected [8]. Using data analysis strategies grounded in the constant comparative method, in which each unit of data is constantly analyzed in comparison with previously collected data [15], I carefully analyzed each participant's data set (interview, observation, and documents) separately, following the same step-by-step process [8].

First, I read and re-read each set of field observation notes until I could distinguish "any meaningful (or potentially meaningful) segment of data" [8, p. 179]. As I read the field notes, I wrote down emerging insights, feelings, tentative concepts, and questions in the margins. Then I checked and revisited the interpretation by comparing it with both the transcripts from the first interview and the first collected documents, to examine the participants' thoughts, perceptions, and feelings before new data collection occurred. Developing a sense of these data as a whole, I again wrote in the margins my feelings, insights, tentative concepts, and questions developed from the interpretation of the entire first data set. Then I reviewed all my marginal notes again and attempted to develop preliminary concepts, categories, and contexts. These themes evolved as new data were added.

The analytical process for the second set of data followed exactly the same design as the analysis of the first data set. However, I made a separate list of comments, questions, and concepts generated from the second phase of analysis, and then compared this list with the list derived from my previous analysis. I then merged the two lists into one, which reflected the conceptual direction of the research to this point. The next set of data and all of the data gathered on an ongoing basis were analyzed chronologically using the same process.

Next, I periodically re-reviewed the interpretation of the whole data set on a weekly and monthly basis, and conducted a preliminary cross-case analysis. I manually coded the data, looking for patterns, categories, and themes emerging from the collected data, comparing and contrasting sets on the basis of these categories, and considering the context of each data set. These comparisons were continually conducted within and between sets of data and between the two participant classrooms.

Lastly, after the analysis of the data from the participants was complete and emergent themes had been identified, I conducted a comprehensive cross-case analysis [17]. I examined the entire body of analysis I had produced throughout the study to refine and confirm or refute my preliminary analyses.

\section{Findings and Discussion}

Regarding research question one, my participants revealed three major themes that they used in pedagogical decision-making and teaching practices for emotional scaffolding. The first theme is beliefs about self-identity, which is defined as inclusive of the teacher's self-perception as a teacher and self-presentation to students [14]. They both employed their beliefs about their self-identities to shape what they saw as appropriate classroom climates, pointing out what they saw as deficit traits for teachers interested in student emotion, and describing ways that they tried to manage their personalities to provide what they saw as appropriate emotional scaffolding.

They performed self-interpretation, identifying what they saw as "constructive" or "unconstructive" characteristics for instruction in their particular contexts. Their awareness of the role of teacher identity in influencing the students' experiences helped them deliberately manage their identities to support student engagement in learning. Each participant's awareness of what she saw as her own personal characteristics allowed her to create more successful engagement in the teaching and learning process - engagement that appeared to help both teacher and student.

This finding had not been addressed in the previous literature about emotional scaffolding [7], [9], [12], [13]. The participants emphasized that, when they make decisions, they consider many factors, but that, in their own terms, "knowing yourself" is a critical part of their decision-making processes. They said that self-examination helped them assess emotional situations and make better decisions. The participants' responses reflect the importance of self-assessment for teaching practices, and reinforce the theory that individual approaches to the emotional side of teaching are part of a process of a teacher's self-formation, not inherently present in the teacher from birth, as the positivist concept of "personality" implies [11].

The second theme was teachers' understanding of their students' emotions. The participants made their decisions about implementing their instructional strategies by drawing on four types of informational sources, moving from the general to the specific: 1) their academic knowledge of how young children learn; 2) their knowledge of how particular group of students learn; 3) their knowledge of their students as individuals; 4) their observations of students' emotional responses in the course of lessons. Although I have split these four types of understanding into defined categories in the classroom, they worked in conjunction to create decisions. These findings are congruent with the literature under review, which described teachers' decision-making as 
using their understanding of student emotion [7], [9], [12]. More specifically, McCaughtry [7] and Rosiek [12] pointed out that teachers' academic knowledge of how students learn is combined with knowledge about how instructional decisions will influence student emotions in decision-making processes regarding emotional scaffolding. The literature also argues that using knowledge about the makeup of a particular class, specifically a group of students who could have marginalized feelings in the school culture, is critical for creating emotional scaffolding [7], [12]. For example, Rosiek [12] discussed an instance in which a high school teacher approached a challenging algebra math lesson about "word problems" with her Latino English language learners (ELL). She implemented a culturally calibrated lesson that could elicit their interests and confidence.

Unlike in Rosiek's example, however, my participants did not approach ELL students by trying to focus on adjusting content-rather, they focused on ELL students' learning styles based on their understanding of how ELL students learn and how emotions could play a role in that learning.. They believed that ELL students were more comfortable representing their ideas and feelings through demonstration using nonverbal communications (e.g., body language, gestures, and facial expressions). Although they believed that ELL students were knowledgeable learners, there was a gap between the ELL children's potential capabilities and their current English skills, which could give them negative emotional experiences in the learning process. In this vein, they believed that this strategy could create a sense of security for them. Unlike the secondary teacher described by Rosiek [12], my participants focused more on altering their presentation style to convey the curriculum content, rather than on changing the presentation content to include the children's culture. They used demonstration teaching and nonverbal communication in alignment with verbal instruction, unlike the secondary teacher who employed verbal instruction as a main communication tool.

The last theme was the participants' feelings about school expectations and academic pressures. Both participants reacted to their school climates by serving as active mediators, meeting mandated curriculum expectations and upholding their pedagogical beliefs by implementing academic-oriented programs that also upheld children's emotional attachments to their classroom and their academic learning. Interestingly, the participants saw school expectations and academic pressures as opportunities to pay more attention to creating teaching strategies for emotional scaffolding, rather than as challenges that would lead them to neglect students' emotions in teaching subject matters. To increase students' academic success, my participants viewed emotions as pivotal in the construction and implementation of teaching strategies for emotional scaffolding. By focusing on emotions in an academic-oriented context, my participants positioned themselves as having mediated agency [5]. Lasky [5] used the term mediated agency to describe the effects of reform climates on teachers' actions in the classroom. This term considers the effect of surrounding structures on teachers' abilities to act on their beliefs and goals through shaping their own classroom strategies. This finding goes unaddressed in the literature on emotional scaffolding. However, this finding is supported by the literature about teachers' emotional experiences arising when implementing educational reform and policy [5]. The literature can be useful in assessing how teachers arrive at their pedagogical decision-making for emotional scaffolding in relation to their feelings about the school context.

Regarding research question two, my participants constructed and implemented emotional scaffolding drawing on four commonalities. In many cases, there was a thin line between construction and implementation of these strategies; teachers were constantly revising their approaches according to their minute-to-minute observations of student emotions. Both participants constructed and implemented their strategies using informed and deliberate decision-making and used a vision of a pedagogically important emotion to shape their strategies. Both participants were aware of pedagogical advantages and disadvantages and ethical dilemmas (e.g., individual attention, fairness, and the use of appropriate touch) that could arise when they implemented their teaching strategies in order to increase children's constructive emotions and decrease unconstructive emotions toward learning [12]. When they paid attention to individual students during whole group activities, both participants struggled to maintain fairness and to avoid unintentional teacher reinforcement of students' images. Their awareness was also connected with their desire to better manage their students. Their goal was not necessarily to maintain discipline, but to create a constructive group situation in order to keep all students actively involved in instruction.

Each teacher tried to apply her idea of the most pedagogically important emotion to her individual students' needs. The preschool teacher believed that her young students most needed a sense of security. Without first establishing that sort of climate, she believed that children would have difficulty engaging in learning experiences. The kindergarten teacher who was in charge of students a year older, believed that excitement was the best way to get her students engaged in learning experiences. However, their emphasis on the single most important emotion may sometimes have led them to predict a child's needs based on a formula, rather than assessing each child on an individual basis. In this sense, to construct an emotional tone for their classrooms, the teachers employed a certain unavoidable degree of manipulation. On the other hand, by having an overarching emotion set the emotional tone of the classroom, my participants were capable of providing a consistent, daily teaching practice for emotional scaffolding. This tradeoff shows how emotional scaffolding can, like any teaching practice, become a habit, which has its positive and negative effects.

My participants focused on balancing excitement with engagement and positioned themselves as protective governors. My participants found that variations in student excitement affected their pedagogical decision-making, 
believing that excitement could hinder or facilitate children's engagement. In general, the literature on the function of various emotions in the classroom considers excitement to be a positive emotion. For example, Linnenbrink [6] divided emotions into pleasant and unpleasant, placing them on a spectrum from low activation to high activation. According to Linnenbrink, excitement is a highly activated, pleasant emotion. My participants, however, operating in the early childhood context, considered excitement to be neither pleasant nor unpleasant, but rather constructive or unconstructive, changing their assessments depending on the context of the classroom discussion. For example, there was the occasion when the preschool teacher discussed different screwdriver and screw types, a child suddenly expressed her excitement about the tools by saying, "My, my daddy used that!" which affected the other students' level of attention. The teacher acknowledged and validated the child's excitement through verbal and nonverbal communications rather than ignoring or rejecting the child's emotion. When the child continually interjected during the lesson, the teacher adjusted her responses to the level of the child's excrement, while balancing her responsibility to maintain learning engagement. In this context, the preschool teacher defined her position as a protective governor, creating a balance between child's emotions and the need to learn about the topic.

Finally, my participants constantly engaged in emotion work through managing emotional expressions and adjusting self-presentation based on their perceived teacherly identity and perceived student needs. When a person controls his/her expression to project an emotion that differs from his/her actual internal state, this is called emotional labor [3]. What I observed in the classrooms was not emotional labor but what is termed emotion work [2]. My participants revealed that they responded to student emotions with voluntary decision-making.

I can represent these findings as a schematization that illustrates the dynamic, interdependent, and complex interaction between factors that influence the process of pedagogical decision-making and practices in early childhood education contexts (see figure 1).

This study shows that the quality of the classroom experience, on both the academic and emotional levels, can improve when the teacher shows conscious awareness of the role of emotion. Importantly, emotional scaffolding can also allow teachers to gain more pleasure from teaching, and contribute to their sense of agency. The findings offer several implications. First, this study expands our perception of the nature of emotional scaffolding processes. My participants showed that emotional scaffolding could occur outside of teacher-initiated verbal interactions. Second, the study has an implication regarding the sufficiency of pre-service training in early childhood education. Both my participants had long experience in the classroom, yet admitted to still being in the process of fine-tuning their emotional teaching practices. How, then, can new teachers approach the question of emotional scaffolding? This study highlights the difficulties and possibilities. Thirdly, there is an implication about the importance of schools' administrative support of teachers and their practices. Both my participants were successful teachers who attributed their success to their freedom to create innovative strategies for emotional scaffolding. Finally, a teacher's self-perception has a large influence on his or her implementation of emotional scaffolding, shaping the way that $\mathrm{s} / \mathrm{he}$ approaches presentation and content.

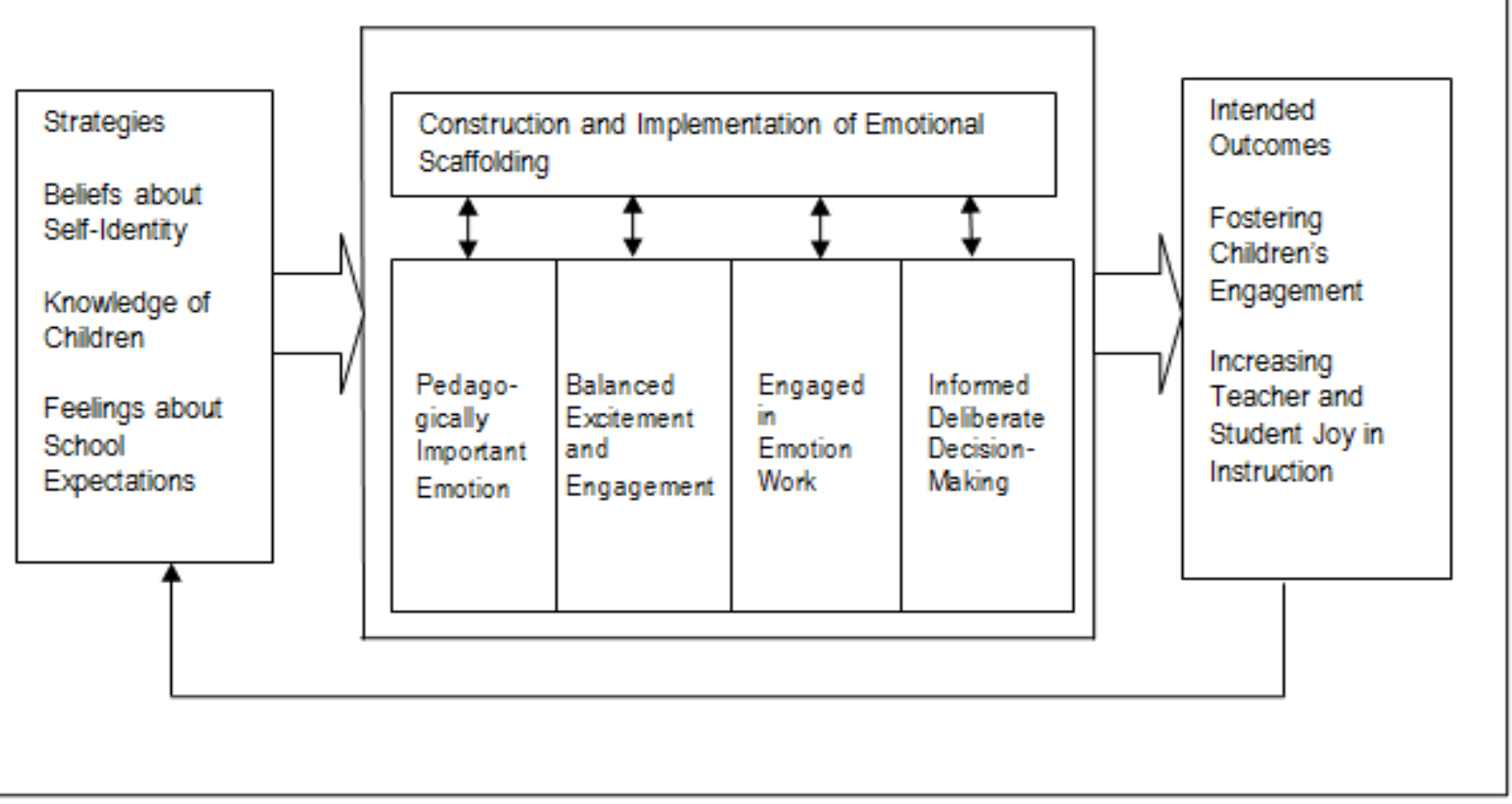

Figure 1. The process of pedagogical decision-making and practices for emotional scaffolding in two early childhood education classrooms 


\section{REFERENCES}

[1] Blair, C. (2002). School readiness: Integrating cognition and emotion in a neurobiological conceptualization of children's functioning at school entry. American Psychologist, 57(2), 111-127.

[2] Callahan, J. L., \& McCollum, E. E. (2002). Obscured variability: The distinction between emotion work and emotional labor. In N. M. Ashkanasy, W. J. Zerbe, \& C. E. Hartel (Eds.), Managing emotions in the workplace (pp. 219-231). Armonk, NY: M. E. Sharpe.

[3] Hochschild, A. (1983). The managed heart: The commercialization of human feeling. Berkeley, CA: University of California Press.

[4] Hyson, M. (2008). Enthusiastic and engaged learners: Approaches to learning in the early childhood classroom. New York, NY: Teachers College Press.

[5] Lasky, S. (2005). A sociocultural approach to understanding teacher identity, agency and professional vulnerability in a context of secondary school reform. Teaching and Teacher Education, 21, 899-916.

[6] Linnenbrink, E. A. (2007). The role of affect in student learning: A multi-dimensional approach to considering the interaction of affect, motivation, and engagement. In P.A. Schutz \& R. Pekrun (Eds.), Emotion in education (pp. 107-124). San Diego, CA: Elsevier Inc.

[7] McCaughtry, N. (2004). The emotional dimensions of a teacher's pedagogical content knowledge: Influences on content, curriculum, and pedagogy. Journal of Teaching in Physical Education, 23, 30-47.

[8] Merriam, S. B. (1998). Qualitative research and case study applications in education. San Francisco, CA: Jossey-Bass.

[9] Meyer, D. K., \& Turner, J. C. (2007). Scaffolding emotions in classrooms. In P.A. Schutz \& R. Pekrun (Eds.), Emotion in education (pp. 243-258). San Diego, CA: Elsevier Inc.

[10] Miller, S. A. (2005). Reflection on kindergarten: Giving young children what they deserve. Childhood Education, 81(5), 256-260.

[11] Nias, J. (1989). Primary teachers talking: A study of teaching as work. London, United Kingdom: Routledge.

[12] Rosiek, J. (2003). Emotional scaffolding: An exploration of the teacher knowledge at the intersection of student emotion and the subject matter. Journal of Teacher Education, 54(5), 399-412.

[13] Rosiek, J., \& Begetto, R. A. (2009). Emotional scaffolding: The emotional and imaginative dimensions of teaching and learning. In P. A. Schutz \& M. Zembylas (Eds.), Advances in teacher emotion research: The impact on teachers' lives (pp. 175-194). New York, NY: Springer.

[14] Schutz, P. A., Cross, D. I., Hong, J. Y., \& Osbon, J. N. (2007). Teacher identities, beliefs, and goals related to emotions in the classroom. In P.A. Schutz \& R. Pekrun (Eds.), Emotion in education (pp. 223-241). San Diego, CA: Elsevier Inc.

[15] Strauss, A., \& Corbin, J. (1998). Basics of qualitative research: Techniques and procedures for developing grounded theory. London, United Kingdom: Sage.

[16] Vygotsky, L. S. (1978). Mind in society: The development of higher psychological processes. Cambridge, MA: Harvard University Press.

[17] Yin, R. K. (2003). Case study research design and methods (3rd ed.). Thousand Oaks, CA: Sage Publications. 